\title{
EVALUATION OF THE EFFECT OF HYDROGEN CHARGING ON THE MECHANICAL PROPERTIES OF IRON-BASED ALLOYS
}

\author{
T. DEPOVER \\ Department of Materials Science \\ and Engineering, Ghent University \\ (UGent), Technologiepark 903, B- \\ 9052 Ghent, Belgium \\ Z. ZERMOUT \\ ArcelorMittal Global R\&D Gent, \\ J.F.Kennedylaan 3, B-9060 Zelzate, \\ Belgium
}

\author{
E. WALLAERT \\ Department of Materials Science \\ and Engineering, Ghent University \\ (UGent), Technologiepark 903, B- \\ 9052 Ghent, Belgium
K. VERBEKEN
Department of Materials Science and Engineering, Ghent University (UGent), Technologiepark 903, B- 9052 Ghent, Belgium

\begin{abstract}
The present work evaluates the effect of hydrogen on the mechanical properties of iron-based alloys by tensile tests. Both uncharged and electrochemically insitu hydrogen charged notched samples were tested using a cross-head speed of $5 \mathrm{~mm} / \mathrm{min}$. These experiments were performed both on advanced multiphase high-strength steels and lab-cast Fe-C alloys. A significant hydrogen embrittlement was observed as ductility dropped with 20 to $60 \%$ under severe $\mathrm{H}$-charging conditions. Considerable differences in behavior were found for the different grades. Fractography was performed by scanning electron microscopy and it was observed that hydrogen charging caused a change from an originally ductile fracture surface to a transgranular cleavage failure near the notch.
\end{abstract}

\section{INTRODUCTION}

The detrimental influence of hydrogen on the mechanical properties of steel was first described by Johnson in 1875 [1]. The loss of ductility is considered the main result of hydrogen embrittlement (HE). Conventional characteristics of plasticity, such as elongation and area reduction are decreased due to the influence of hydrogen. Several reference works by Bernstein [2], Oriani [3, 4] and Troiano [5] described this phenomenon in detail, but up to now, some features remain unexplained and hydrogen related fracture can still occur in an unpredictable way. Hydrogen is often quoted as the future energy carrier as it might offer an alternative for the scarce fossil fuels. Furthermore, in the automotive industry, weight reduction at the same strength level is one of the main goals to reduce the fuel consumption and hence the $\mathrm{CO}_{2}$ emission. High strength steels are good candidates for many structural applications due to their good strength to weight ratio. However, these steels are more prone to HE [6].

In the present study, the influence of hydrogen on the mechanical properties of iron-based alloys was investigated by tensile tests on in-situ hydrogen charged samples. An overview is given on some results of both industrial high strength steels and iron-based lab-cast materials. The interaction of these materials with hydrogen was already investigated in detail by Thermal Desorption Spectroscopy (TDS) and hot/melt extraction in previous work [7$10]$. 


\section{EXPERIMENTAL PROCEDURE}

Four different high-strength multiphase steels were used throughout this study. FB is a ferritic-bainitic steel; TRIP is a multiphase steel containing ferrite, bainite and retained austenite; DP is a ferritic-martensitic dual phase steel; S550MC is a high strength low alloy (HSLA) steel that contains ferrite, pearlite and $\mathrm{Ti}-\mathrm{Nb}$ based precipitates. To increase the understanding in the behavior of the different phases present in the industrial materials, lab-cast, generic Fe-C alloys were designed. The combination of variable carbon content and appropriate heat treatments allowed to obtain separately the different phases present in the industrial materials and consequently to learn more about their behavior. The chemical compositions are presented in Table 1 .

\begin{tabular}{|c|c|c|c|c|}
\hline Material/Element & C & Mn & Si & Other \\
\hline TRIP & 0.17 & 1.60 & 0.40 & $1 \%-2 \% \mathrm{Al}, 0.04 \%-0.1 \% \mathrm{P}$ \\
\hline FB & 0.07 & 1.00 & 0.10 & $0.5 \%-1.0 \% \mathrm{Cr}$ \\
\hline DP & 0.07 & 1.50 & 0.25 & $0.4 \%-0.8 \% \mathrm{Cr}+\mathrm{Mo}$ \\
\hline HSLA & 0.07 & 0.95 & 0.00 & $0.08 \%-0.12 \% \mathrm{Ti}+\mathrm{Nb}$ \\
\hline Pure Iron & 0.0015 & 0.0003 & 0.00 & $<0.02 \% \mathrm{Al}, \mathrm{P}$ \\
\hline $\mathbf{0 . 2 \%} \mathbf{C}$ & 0.199 & 0.004 & $<0.0002$ & $<0.0008 \mathrm{P}, \mathrm{N}$ \\
\hline $\mathbf{0 . 4 \%} \mathbf{C}$ & 0.374 & 0.002 & $<0.0001$ & $<0.0007 \mathrm{P}, \mathrm{N}$ \\
\hline
\end{tabular}

Table 1: Chemical composition of the materials in wt\%.

The generic alloys were produced in a Pfeiffer VSG100 vacuum melting and casting unit, operating under an argon gas protective atmosphere. Both the industrial and the lab-cast alloys were hot and cold rolled. Pure iron (PI) was annealed at $750^{\circ} \mathrm{C}$ for 10 minutes in an air furnace and air cooled. Appropriate heat treatments were applied on the $0.2 \%$ and $0.4 \%$ of $\mathrm{C}$ steel grades in order to form bainitic (B2 with $0.2 \% \mathrm{C}$ and B4 with $0.4 \% \mathrm{C}$ ) or pearlitic phases (P2, with $0.2 \% \mathrm{C}$ ). Temperature vs. time graphs for each phase are given in Fig. 1 and discussed more in detail in $[9,11]$.
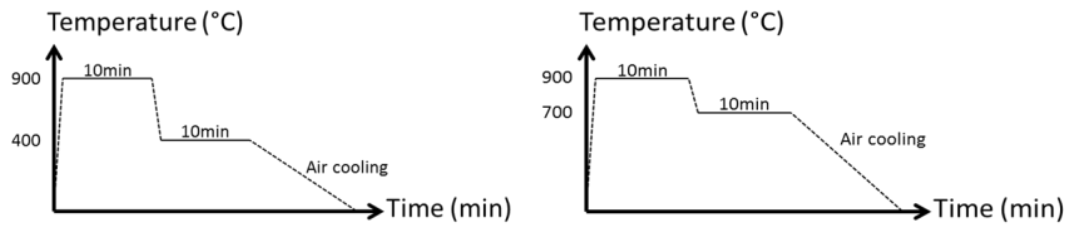

Figure 1: Temperature-time graphs for different heat treatments: (left) bainite and (right) pearlite

The tensile samples were made by spark erosion, with the tensile axis parallel to the rolling direction. The sample surfaces were sand blasted to remove the oxides. Optical microscopy was performed to characterize the materials. Details about the sample preparation are available in $[7,8,12]$ for the industrial high-strength steels and in $[9,11]$ for the lab-cast alloys. In order to study the influence of $\mathrm{HE}$, the tensile tests were performed in air (uncharged) and in charged conditions. Charged samples were prepared by cathodic $\mathrm{H}$ charging using a $1 \mathrm{~g} / \mathrm{L}$ thiourea $0.5 \mathrm{M} \mathrm{H}_{2} \mathrm{SO}_{4}$ based solution. The materials were 
charged for 2 hours at a current density of $2.65 \mathrm{~mA} / \mathrm{cm}^{2}$, these conditions were confirmed to generate complete hydrogen saturation of the samples [7-12]. It should be noted that these conditions are very severe and not representative of in-use conditions. In fact, the motivation was to get a ranking during an accelerated test. To control crack initiation, notched tensile samples were used. This geometrical discontinuity gave rise to a local stress concentration expressed by a stress concentration factor $\mathrm{K}_{\mathrm{t}}$ of 4.2. After charging, tensile tests were performed using a cross-head displacement speed of $5 \mathrm{~mm} / \mathrm{min}$. In order to evaluate the hydrogen effect, an embrittlement index (EI) was defined as:

$$
\mathrm{EI}=\frac{\text { Elongation in Air }- \text { Elongation when Charged }}{\text { Elongation in Air }}
$$

Eq. 1

Hence, EI can vary between 0 and 1, with 0 meaning that there is no ductility drop and that the material is insensitive to HE. When an index of 1 is obtained, the ductility drop is $100 \%$ and the HE is maximal. In addition, another index $\left(\mathrm{EI}_{\mathrm{RA}}\right)$, as described in Eq.2, based on the reduction of area (RA) was determined based on Scanning Electron Microscope (SEM) images. SEM measurements were performed using a FEI ESEM XL30.

$$
\mathrm{EI}_{\mathrm{RA}}=\frac{\mathrm{RA}_{\text {Air }}-\mathrm{RA}_{\text {Charged }}}{\mathrm{RA}_{\text {Air }}}
$$

\section{MATERIALS CHARACTERIZATION}

The optical micrographs of the lab-cast materials are presented in Fig. 2, the pictures for the high-strength industrial steels can be found elsewhere $[7,8,12]$.

a
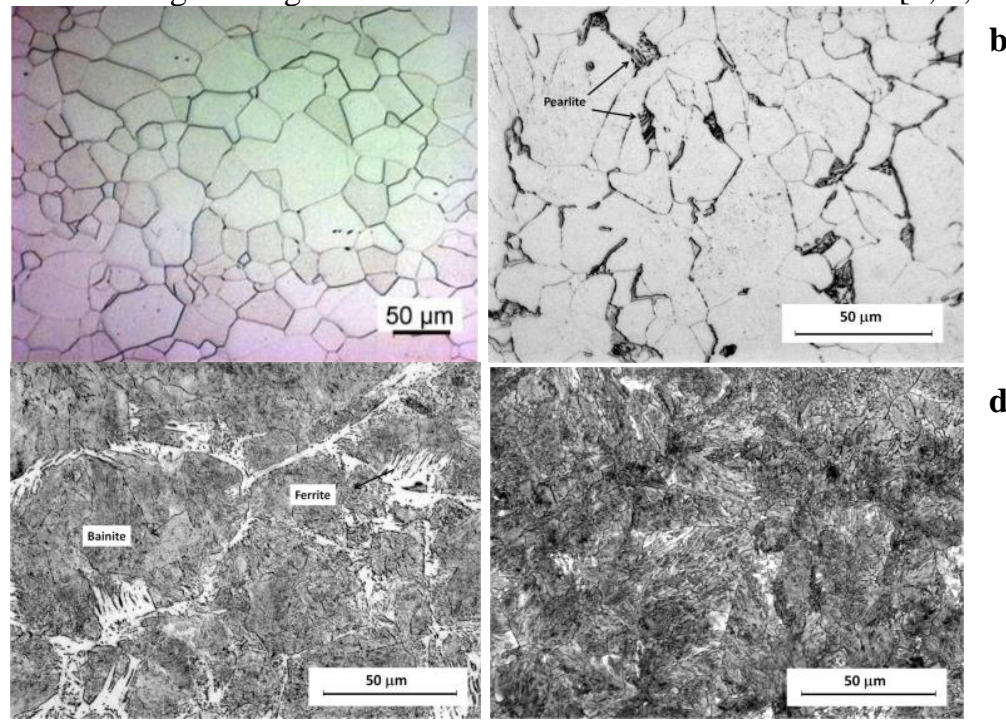

Figure 2: Optical micrographs of Pure iron (a), P2 (b), B2 (c) and B4 (d). 


\section{RESULTS AND DISCUSSION}

\section{Multiphase high-strength steels}

The results of the tensile tests on the high-strength steels are summarized in Fig. 3 and in Table 2. Each test was performed twice to verify the reproducibility of the results: two identical test conditions are labeled as " $\mathrm{A}$ " and "B". Fig. 3 clearly illustrates the good reproducibility of the experiments.
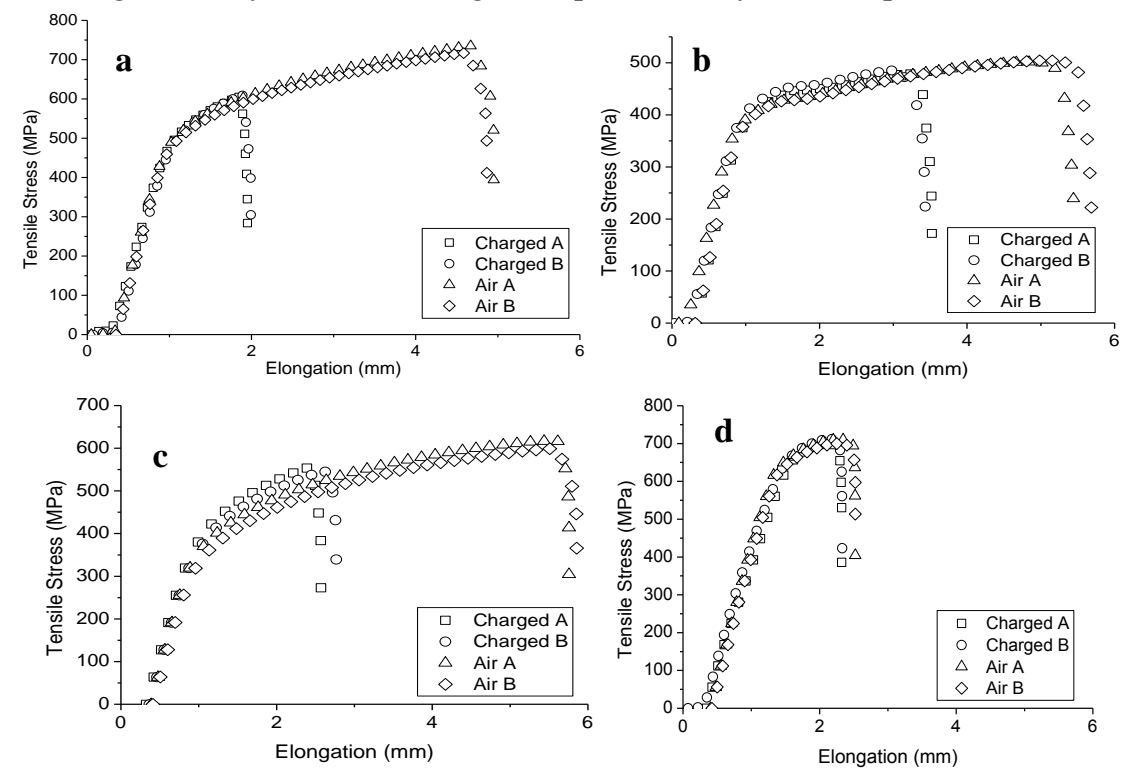

Figure 3: Stress-strain curves for TRIP (a), FB (b), DP (c) and HSLA (d), with equivalent tests indicated with "A" and "B". Tests performed at a cross-head speed of $5 \mathrm{~mm} / \mathrm{min}$.

\begin{tabular}{|c|c|c|}
\hline Material & tensile test index $(\mathbf{E I})$ & reduction of area index $\left(\mathbf{E I}_{\mathbf{R A}}\right)$ \\
\hline TRIP & 0.60 & 0.60 \\
\hline DP & 0.54 & 0.52 \\
\hline FB & 0.37 & 0.36 \\
\hline HSLA & 0.08 & 0.12 \\
\hline
\end{tabular}

Table 2: Overview of the indices determined by tensile tests and SEM images at a cross-head speed of $5 \mathrm{~mm} / \mathrm{min}$, as described above in Eq. 1 and 2 .

Under the very severe charging conditions, the highest EI (60\%) was measured for the TRIP steel. The ductility of the DP steel dropped 54\%, while the FB steel had an EI of 37\%. A clearly higher ductility retention was observed for the HSLA steel. This steel, which contained $\mathrm{Nb}$ and $\mathrm{Ti}$ precipitates, remained almost intact after charging.

Several reasons might contribute to the large ductility drop for the TRIP steel. At first, this steel has a higher tensile strength and the hydrogen effect is more pronounced with increasing strength level, as reported by Oriani [3], 
Troiano [5], Bernstein and Thompson [13, 14]. Secondly, the strain induced transformation of the retained austenite might play a role. The detrimental effect of martensite in the microstructure was confirmed by the relatively high EI for the DP steel. Additionally, it should be taken into account that the solubility of hydrogen in a face centered cubic (FCC) crystal lattice is higher than in a body centered cubic lattice (BCC). The presence of hydrogen in the retained austenite was demonstrated elsewhere [10], and consequently gave rise to a hydrogen oversaturated strain induced martensite. This might have an embrittling effect on the TRIP steel. Thirdly, the higher amount of carbon (see Table 1) in the TRIP samples could play a role. Moreover, the carbon content in retained austenite was determined to be $1.2 \%$ [10], which implies that the strain induced martensite also contains a considerable amount of carbon. The carbon content also affects the hydrogen saturation level of the BCC phase [9].

The EI of FB is significantly lower than for DP or TRIP steel. One reason for this could be the low amount of secondary phase, as FB only contains $3.4 \%$ bainite, while DP has $23.6 \%$ martensite and TRIP the highest amount of nonferritic phases [12]. Remarkable are the results for the HSLA steel. This material with $\mathrm{Nb}$ and $\mathrm{Ti}$ precipitates shows almost no effect of $\mathrm{HE}$ after charging. An explanation for this is the presence of precipitates, which strongly trap hydrogen. TiC has been often quoted to be an irreversible trap with high activation energy. For example, Pressouyre and Bernstein [15, 16] determined that titanium additions greatly reduced degradation, gave rise to strong hydrogen traps and prevented hydrogen from reaching more damaging second-phase particles or reversible hydrogen traps. TDS (thermal desorption spectroscopy) work done by Escobar et al. [7] demonstrated that the HSLA steel had the highest hydrogen trapping capacity of all industrial materials. This indicated that the desorption kinetics are slower for the HSLA grade and that consequently the hydrogen is more strongly trapped by the $\mathrm{Ti}$ - and Nb-based precipitates. Duprez et al. [17] also demonstrated, using another experimental approach, the low hydrogen sensitivity of HSLA steel.

Apart from the microstructural features, the hydrogen diffusivity during the mechanical test is also of importance, since it will allow hydrogen to interact with both crystal defects and cracks generated during the tensile test. In the present work, hydrogen diffusion during the tensile test is expected to be minimal because of the relatively high cross-head speed. At slower cross-head speeds, diffusible hydrogen will have more time to migrate towards the crack tip where it will cause a more brittle zone and fracture propagation will be enhanced. As presented elsewhere, experiments at $0.05 \mathrm{~mm} / \mathrm{min}$ confirmed these expectations [12]. Similar work by Toh and Baldwin [18] also demonstrated that the RA decreased with increasing cross-head speed.

Fractography results obtained in the present work are shown in Fig. 4 [12]. The fracture surface of the uncharged sample shows fine dimples indicating a ductile fracture with considerable necking. For the charged sample the necked region is clearly smaller due to $\mathrm{HE}$. Hydrogen caused a change from a ductile, microvoid coalescence failure, to a predominantly faceted, brittle transgranular cleavage failure after hydrogen charging with a transition zone near the edges. This is in good agreement with the results obtained in [6]. 

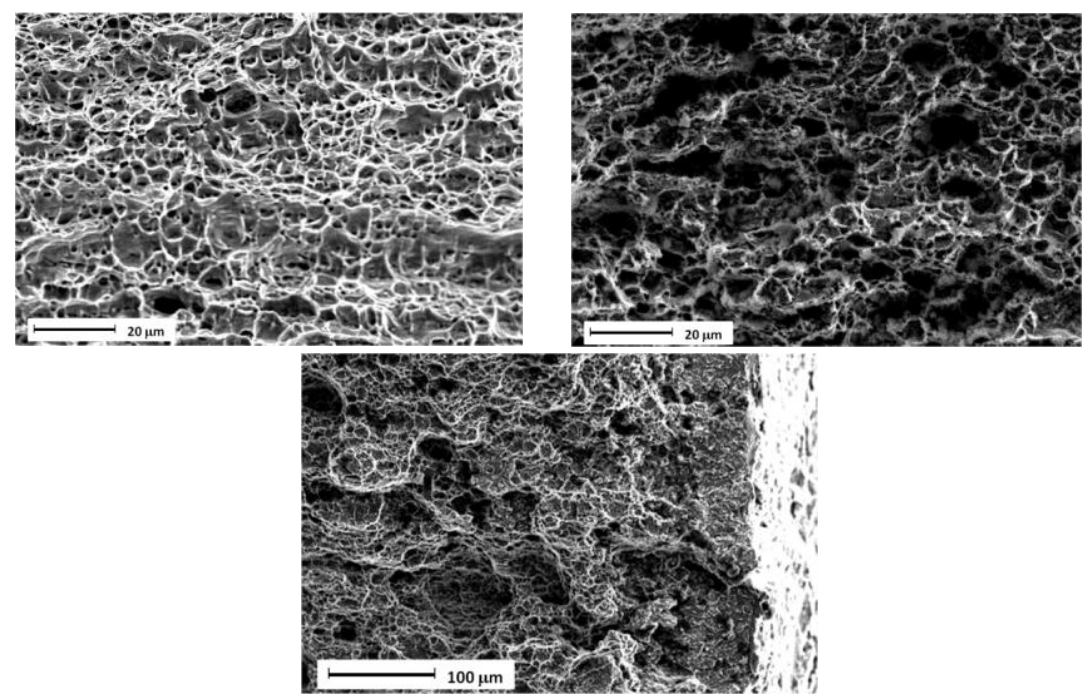

Figure 4: SEM images (DP steel) of the uncharged fracture surface (top left), the charged fracture surface (top right) and the surface near the edge (centre).

\section{Lab-cast alloys}

The tensile test results of the generic lab-cast alloys at a cross-head speed of $5 \mathrm{~mm} / \mathrm{min}$ are summarized in Fig. 5 and in Table 3.
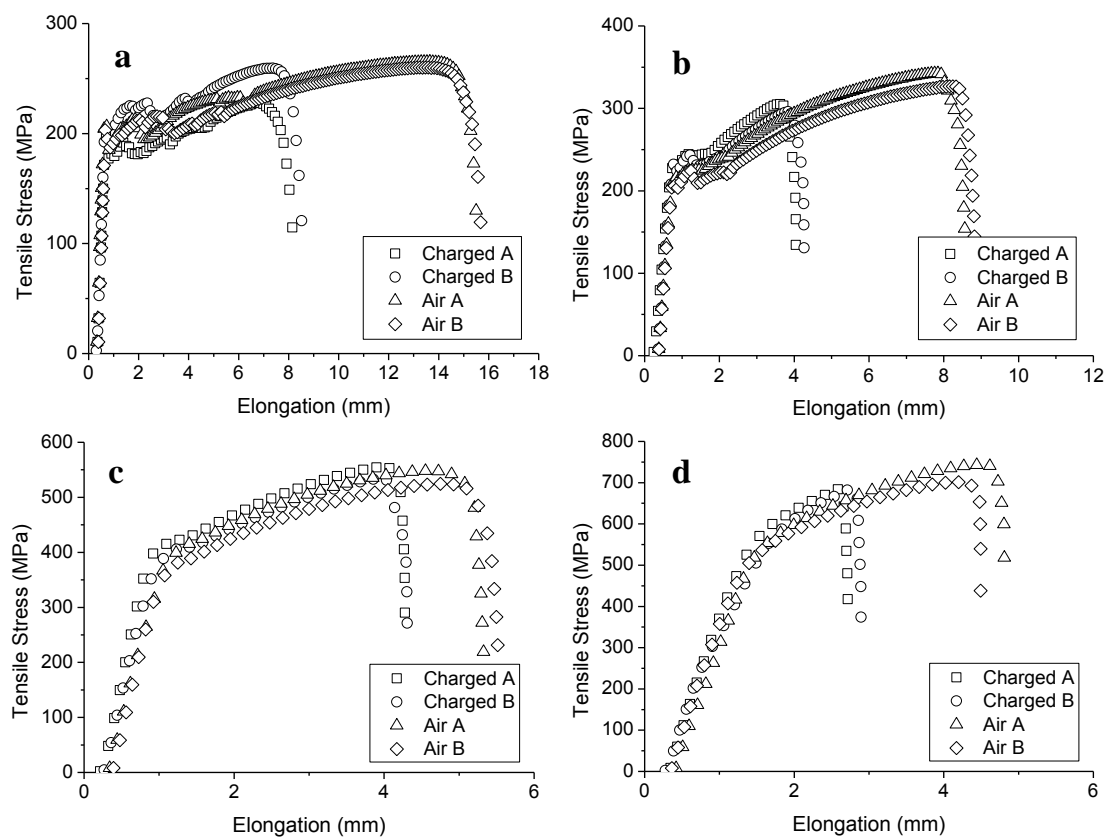

Figure 5: Stress-strain curves for the Pure Iron (a), P2 (b), B2 (c) and B4 (d) alloy performed at cross-head speed of $5 \mathrm{~mm} / \mathrm{min}$. 


\begin{tabular}{|c|c|c|}
\hline Material & tensile test index (EI) & reduction of area index $\left(\mathbf{E I}_{\mathbf{R A}}\right)$ \\
\hline $\begin{array}{c}\text { Pure Iron } \\
\text { (PI) }\end{array}$ & 0.46 & 0.48 \\
\hline P2 & 0.52 & 0.54 \\
\hline B2 & 0.21 & 0.23 \\
\hline B4 & 0.40 & - \\
\hline
\end{tabular}

Table 3: Summary of the EI of the lab-cast materials [11]

The ductility drop for pure iron after H-charging was about $46 \%$. This is remarkable as pure iron only contains a limited amount of traps such as grain boundaries, vacancies or dislocations. Blister maps obtained by Escobar et al. [9] showed that the used charging conditions gave rise to damage of the sample as blisters and internal cracks appeared. This could be correlated with the high EI for pure iron. When the microstructures are considered, it was not surprising that the stress-strain curves of P2 and PI looked similar. The pearlitic sample (Fig. 2b), in comparison with the bainitic sample (Fig. 2c), consisted mainly of ferrite $(6.8 \% \mathrm{Pe}+93.2 \% \alpha)$ [11]. An EI of 52\% was obtained for P2, which could be linked with the higher carbon content, introduced in the microstructure as cementite. It was also shown that adding carbon increased the amount of diffusible hydrogen [11].

For the bainitic grades B2 and B4, a higher EI was achieved for the latter. This could be correlated with the higher amount of bainite in B4 (98\% B) compared to B2 $(89 \% \mathrm{~B})$, due to the higher carbon amount in B4 [11]. An almost fully bainitic microstructure was obtained for B4, while some Widmanstätten ferrite arose in B2, see Fig. 2.

According to literature, the susceptibility to hydrogen degradation increases in the order of bainite, quenched martensite and pearlite [19]. The same order was achieved here. More details about the fractography and the influence of cross-head speed on the embrittlement can be found elsewhere [11].

\section{CONCLUSIONS}

Tensile tests with in-situ hydrogen charging were performed on iron-based alloys. The experiments showed a considerable ductility loss of these materials due to hydrogen pick-up. The correlation between the strength of the material and the degree of HE was confirmed, except for the HSLA steel, where the enhanced HE resistance could be linked to the presence of $\mathrm{Ti}$ and $\mathrm{Nb}$ based precipitates. The established index based on the elongation was in good agreement with the one based on the reduction of area. The fracture surface of the uncharged samples showed a considerable ductile necking zone, while the hydrogen charged samples showed a brittle transgranular cleavage failure near the edges, with transition zone to some ductile features in the centre. It was argued that the carbon content plays an important role. However, since various phenomena influence the results, more experiments are necessary to better understand the mechanisms governing the steel-hydrogen interaction. 


\section{ACKNOWLEDGEMENTS}

The authors wish to thank the Special Research Fund (BOF), UGent (BOF10/ZAP/121) and the Agency for Innovation by Science and Technology in Flanders (IWT) for support (Project nr SB111205). The authors also acknowledge the technicians and staff working at the hydrogen laboratory at OCAS (ArcelorMittal R\&D Gent) and the technical staff from the Department Materials Science and Engineering, UGent, for their help with the experiments and sample preparation.

\section{REFERENCES.}

[1] Johnson, W.H., 1875, "On some remarkable changes produced in iron and steel by the action of hydrogen and acids," Proceedings of the Royal Society of London, 23A, pp.168-179.

[2] Bernstein, I.M., 1970, Mater. Sci. Eng., 6, pp.1-19.

[3] Oriani, R.A., 1978, Ann. Rev. Mater. Sci., 8, pp. 327-357.

[4] Oriani, R.A., Hirth, J.P., and Smialowski, M., 1985, "Hydrogen degradation of ferrous alloys", Noyes Publications, Park Ridge (NJ).

[5] Troiano, A.R. in: Bernstein, I.M., Thompson, A.W. (Eds.), 1974, Hydrogen in metals, ASM, Metals Park, OH, pp. 3-16.

[6] Hilditch, T.B., Lee, S-B., Speer, J.G., and Matlock, D.K., 2004, "Response to hydrogen charging in high strength automotive sheet steel products", Society of Automotive Engineers, Inc., Colorado School of Mines.

[7] Pérez Escobar, D., Verbeken, K., Duprez, L., and Verhaege, M., 2012, "Evaluation of hydrogen trapping in high strength steels by thermal desorption spectroscopy", Materials Science and Engineering A, 551, pp. 50-58.

[8] Pérez Escobar, D., Miñambres, C., Duprez, L., Verbeken, K., and Verhaege, M., 2011, "Internal and surface damage of multiphase steels and pure iron after electrochemical hydrogen charging", Corrosion Science, 53, pp. 3166-3176.

[9] Pérez Escobar, D., Depover, T., Wallaert, E., Duprez, L., Verhaege, M., and Verbeken, K., 2012, "Thermal desorption spectroscopy study of the interaction between hydrogen and different microstructural constituents in lab cast Fe-C alloys", Corrosion Science, DOI information: 10.1016/j.corsci.2012.08.017.

[10] Pérez Escobar, D., Depover, T., Duprez, L., Verbeken, K., and Verhaege, M., 2012, “Combined TDS, DSC, SEM and XRD study of hydrogen trapping in cold deformed TRIP steel”, Acta Materialia, 60, pp. 2593-2605.

[11] Depover, T., Perez Escobar, D., Wallaert, E., Zermout, Z., and Verbeken, K., 2012, unpublished results.

[12] Depover, T., Perez Escobar, D., Wallaert, E., Zermout, Z., and Verbeken, K., 2012, "Effect of in-situ hydrogen charging on the mechanical properties of advanced high-strength steels", Materials Science and Engineering A, submitted paper.

[13] Bernstein, I.M. and Thompson, A.W., 1960, Trans. ASM, 52, pp. 54-80.

[14] Bernstein, I.M. and Thompson, A.W., 1976, "Effect of Hydrogen on Behavior of Materials", $T M S-A I M E$.

[15] Pressouyre, G.M. and Bernstein, I.M., 1979, Acta Mat., 27, pp. 89-100.

[16] Pressouyre, G.M., 1977, Ph.D. thesis, Carnegie-Mellon University, Pittsburgh, PA.

[17] Duprez, L., Verbeken, K., and Verhaege, M., 2009, "Effect of hydrogen on the mechanical properties of multiphase high strength steel", Proceedings of the 2008 international hydrogen conference, eds. Somerday B.P. et al., ASM International.

[18] Toh, T., and Baldwin, W.M., 1956, eds. Robertson W.D., Stress Corrosion Cracking and Embrittlement. New York : Wiley, pp. 176-186

[19] Thompson, A.W., and Bernstein, I.M., 1979, Adv. Corros. Sci. Technol., 7, pp. 53-175. 